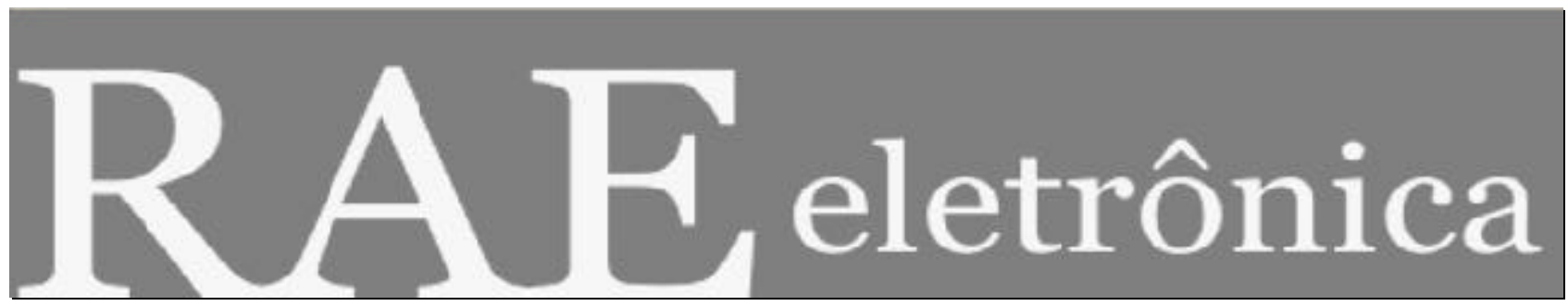

\title{
ASSÉDIO MORAL - UM ENSAIO SOBRE A EXPROPRIAÇÃO DA DIGNIDADE NO TRABALHO
}

Por:

\section{Roberto Heloani}

RAE-eletrônica, v. 3, n. 1, Art. 10, jan./jun. 2004

http://www.rae.com.br/eletronica/index.cfm?FuseAction=Artigo \&ID=1915\&Secao=PENSATA\&Volu $\mathrm{me}=3 \& \mathrm{~N}$ umero $=1 \& A n o=2004$

CCopyright, 2004, RAE-eletrônica. Todos os direitos, inclusive de tradução, são reservados. É permitido citar parte de artigos sem autorização prévia desde que seja identificada a fonte. A reprodução total de artigos é proibida. Os artigos só devem ser usados para uso pessoal e nãocomercial. Em caso de dúvidas, consulte a redação: redacao@ rae.com.br.

A RAE-eletrônica é a revista on-line da FGV-EAESP, totalmente aberta e criada com o objetivo de agilizar a veiculação de trabalhos inéditos. Lançada em janeiro de 2002, com perfil acadêmico, é dedicada a professores, pesquisadores e estudantes. Para mais informações consulte o site www.rae.com.br/eletronica.

RAE-eletrônica

ISSN 1676-5648

(C2004 Editora: Fundação Getulio Vargas - Escola de Administração de Empresas de São Paulo

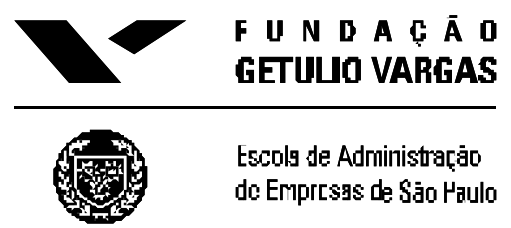




\title{
ASSÉDIO MORAL - UM ENSAIO SOBRE A EXPROPRIAÇÃO DA DIGNIDADE NO TRABALHO
}

\begin{abstract}
Alguns autores costumam colocar a questão do assédio moral como essencialmente individual, como uma "perversão do ego" no âmbito estritamente psicopatológico, em que se dá um silencioso assassinato psíquico. Entre os mais conhecidos, podemos citar aquela que popularizou o conceito, Marie France Hirigo yen, em sua primeira obra Assédio moral: a violência perversa no cotidiano, embora em sua segunda obra, Mal estar no trabalho: redefinindo o assédio moral, essa autora relativize a variável idiossincrática.
\end{abstract}

A par disso, existe uma outra concepção à qual nos filiamos que, não obstante mais complexa, também considera cada indivíduo como produto de uma construção sócio-histórica.. Sujeito e produtor de inter-relações que ocorrem dentro do meio-ambiente social, com suas leis e regras. Diretrizes estas que funcionam dentro de uma determinada lógica macroeconômica, a qual subentende e incorpora relações de poder.

Costumamos dizer que a discussão sobre assédio moral é nova. O fenômeno é velho.Tão velho quanto o trabalho, isto é, quanto o homem, infelizmente...

No Brasil colônia, índios e negros foram sistematicamente assediados, ou melhor, humilhados por colonizadores que, de certa forma, julgavam-se superiores e aproveitavam-se dessa suposta superioridade militar, cultural e econômica para impingir-lhes sua visão de mundo, sua religião, seus costumes.

Não raro esse procedimento, constrangedor sob vários aspectos, vinha acompanhado de um outro que hoje denominamos assédio sexual, ou seja, constranger-se uma pessoa do sexo oposto ou do mesmo sexo a manter qualquer tipo de prática sexual sem que essa verdadeiramente o deseje.

De fato, relembrando as idéias de Gilberto Freyre, em sua obra clássica Casa-Grande \& Senzala: formação da família brasileira sob o regime da economia patriarcal, as relações entre brancos e "raças de cor" foram, no Brasil, condicionadas bilateralmente - de um lado pela monocultura latifundiária ( o cultivo de cana-de- açúcar) no que diz respeito ao sistema de produção econômica; e de outro, pelo sistema sócio-familiar de cunho patriarcal, que se caracterizava pela escassez de mulheres brancas na colônia. Essa monocultura açucareira acabou impossibilitando a existência de uma policultura e de uma pecuária que pudessem se instalar ao redor dos engenhos, suprindo-lhes, inclusive, as carências alimentares. A criação de gado deslocou-se para o sertão, e a casa-grande adquiriu características essencialmente feudais - senhores de engenho, em sua maior parte patriarcais e devassos, que dominavam, do alto de suas moradias, escravos, lavradores e agregados, com mão-deferro.

Sem querermos radicalizar ou extrapolar, considerando a atual sociedade brasileira nos moldes da escravocrata, pensamos que a humilhação no trabalho, ou o assédio moral, sempre existiu, historicamente falando, nas mais diferentes formas. Humilhação esta embasada no próprio sistema macroeconômico, que, em seu processo disciplinar, favorece o aparecimento dessa forma de violência, em que o superior hierárquico detém um certo poder sobre seu subordinado. 
Em um mundo que passa por grandes e rápidas mudanças, as organizações nacionais, pressionadas pelo processo de globalização, substituem cada vez mais o homem pela máquina. Assim, novas tecnologias são implementadas nas empresas, obrigando o trabalhador a adaptar-se rapidamente a elas e impondo um novo perfil profissional tecnicizado.

Fruto de um processo cada vez mais intenso de globalização, de automação fabril, de informatização nos serviços e de agilização nos processos, a hipercompetitividade é um fenômeno recente, que vem chegando ao Brasil e, efetivamente, estimula a instrumentalização do outro.

Nessa nova lógica pós-moderna ou pós-fordista, como queiram, que legitima uma ampla reestruturação produtiva, onde os salários sofrem cada vez mais reduções e a educação emerge como "salvadora" e principal ferramenta da atualização, o trabalho torna-se cada vez mais precário e seletivo. O Estado vem, mediante uma ideologia neoliberal, retirar e diminuir benefícios e direitos do trabalhador, modificando a relação capital-trabalho; surgem, então, novas relações, como o contrato de trabalho por tempo determinado e várias formas de terceirização, que geram, desse modo, o subemprego e o trabalho informal, novas ameaças ao trabalhador, que antes tinha a garantia de alguns direitos historicamente consolidados.

Busca-se desse modo um paradoxo: a conciliação de dois sujeitos historicamente desiguais, capital e trabalho. Por meio de discursos de cooperação e de trabalho em equipe, consultores organizacionais acabam por perpetuar elementos antagônicos: a recessidade da cooperação em equipe e a competição pela aquisição e manutenção de um posto de trabalho.

Essa hipercompetitividade não seria em si mesma uma forma de violência? Uma guerra, como bem coloca Christophe Dejours em A banalização da injustiça social , onde o fundamental não é o equipamento militar, mas o desenvolvimento da competitividade; em que o fim pode justificar os meios, mediante um atropelamento da ética, da própria dignidade humana.

É certo que a violência faz parte da própria condição humana, como o amor, o ódio, o poder, a submissão, o orgulho, a inveja e tantas outras facetas da personalidade. Mas, como Roberto Da Matta em A violência brasileira lucidamente posiciona, não se pode deixar de investigar o conjunto de valores que estão associados a certas formas de violência em sociedades específicas.

Em um sistema em que a "racionalidade instrumental" se sobrepõe à "racionalidade comunicativa" ,(para usarmos a expressão de Habermas em Teoria de la acción comunicativa: crítica de la razón funcionalista ), o que gera uma distorção comunicacional, a violência torna-se uma resposta a um sistema desumano e não pode ser considerada um mero mecanismo individual. Em outras palavras, nesse processo a violência passa a ser uma perversão da perversão, ou seja, uma armadilha motivada pela crueldade do sistema.

Em nossa opinião, a violência reflete, tal como uma imagem no espelho, as formas de poder constituídas socialmente. Se for certo que o furor expansionista do capital conquistou-nos financeiramente, é também exato que nesse processo de expansão comprometeuse o nosso discernimento, ou melhor, a nossa saúde moral. Alguns fragmentos de discurso como "enxugar as gorduras", "exterminar os dinossauros" e mesmo "fazer uma faxina" são expressões recorrentes m "mídia especializada", que costumamos chamar de subliteratura organizacional. 


\section{Situando o assédio moral}

O assédio moral foi apontado como objeto de pesquisa, em 1996, na Suécia, pelo psicólogo do trabalho Heyns Leymann, que, por meio de um levantamento junto a vários grupos de profissionais chegou a um processo que qualificou de psicoterror, cunhando o termo mobbing (um derivado de $m o b$, que significa horda, bando ou plebe), devido à similaridade dessa conduta com um ataque rústico, grosseiro.

Dois anos após, Marie-France Hirigoyen, psiquiatra e psicanalista com grande experiência como psicoterapeuta familiar, popularizou o termo por meio do lançamento de seu livro Le harcèlement moral : la violence perverse au quotidien, um best-seller que ocasionou a abertura de inúmeros debates sobre o tema, tanto na organização do trabalho como na estrutura familiar.

Com formação em "victimologia" na França e nos Estados Unidos, a postura de Hirigoyen é empática em relação à vítima e discordante de algumas teorias psicanalíticas que debitam boa parte da culpa ao agredido, como se de certa forma este estivesse conivente com o agressor ou desejasse inconscientemente a própria situação de agressão, por masoquismo ou mesmo por expiação de culpa. Provavelmente foi essa faceta inovadora e humana de sua abordagem o que motivou o enorme sucesso de seu livro e fez com que, em sua esteira, uma revista francesa, Rebondir, especializada em informações sobre o emprego, realizasse uma vasta pesquisa, em empresas francesas, referente ao assédio moral.

\section{Explicitando o fenômeno}

Para esboçarmos, em linhas gerais, em que consiste o assédio moral, utilizaremos, inicialmente, algumas definições sobre essa conduta, apresentadas por Leymann, Hirigoyen, Barreto e Freitas para depois nos posicionarmos.

De acordo com Heyns Leymann em Mobbing: la persécution au travail,o autor que primeiro detectou esse fenômeno, trata-se de um conceito que se desenvolve em uma situação comunicativa hostil, em que um ou mais indivíduos coagem uma pessoa de tal forma que esta é levada a uma posição de fraqueza psicológica.

Segundo Marie-France Hirigoyen ,que em Assédio moral: a violência perversa no cotidiano,disseminou amplamente a problemática desse sofrimento invisível,o assédio em local de trabalho está ligado a qualquer conduta abusiva em relação a uma pessoa (seja por comportamentos, palavras, atos, gestos ou escritas) que possa acarretar um dano à sua personalidade à sua dignidade ou mesmo à sua integridade física ou psíquica, podendo acarretar inclusive perda de emprego ou degradação do ambiente de trabalho em que a vítima está inserida.

No Brasil, Margarida Barreto notabilizou-se por uma ampla pesquisa junto a 2072 trabalhadores de 97 empresas dos setores químico, farmacêutico, de plásticos e similares, de portes variados, dentro da região da grande São Paulo. Em seu entender, assédio moral ou violência moral no trabalho é a exposição de trabalhadores a situações vexatórias, constrangedoras e humilhantes durante o exercício de sua função, de forma repetitiva, caracterizando uma atitude desumana, violenta e antiética nas relações de trabalho,assédio este realizado por um ou mais chefes contra seu subordinado.

Outra pesquisadora brasileira, Maria Ester de Freitas ,em seu artigo Assédio moral e assédio sexual: faces do poder perverso nas organizações, posiciona ,com justeza, que esse fenômeno se conecta ao 
esforço repetitivo de desqualificação de uma pessoa,que, dependendo das circunstâncias, pode levar ou não ao assédio sexual.

Em nosso entender, o assédio moral caracteriza-se pela intencionalidade; consiste na constante e deliberada desqualificação da vítima, seguida de sua conseqüente fragilização, com o intuito de neutralizá- la em termos de poder. Esse enfraquecimento psíquico pode levar o indivíd uo vitimizado a uma paulatina despersonalização. Sem dúvida, trata-se de um processo disciplinador em que se procura anular a vontade daquele que, para o agressor, se apresenta como ameaça.

Essa dose de perversão moral - algumas pessoas sentem-se mais poderosas, seguras e até mesmo mais autoconfiantes à medida que menosprezam e dominam outras - pode levar com facilidade, a nosso ver, ao assédio moral, quando aliada à questão da hipercompetitividade.

Ou seja, a perversidade (por vezes ligada a traços como frieza, calculismo e inteligência) e encorajada por práticas organizacionais danosas (corrosão de valores éticos essenciais) acaba por desconsiderar o outro, em um verdadeiro extermínio psíquico, calculado e covarde, em relação à pessoa a quem, no íntimo, o agressor inveja.

Bons em fazer política na organização e hábeis em decisões difíceis e polêmicas, esses agressores não raro são admirados por sua relativa eficiência e eficácia em sua performance em curto prazo, apesar da arrogância e do menosprezo com que tratam seus subordinados.

$\mathrm{Na}$ verdade, esses agressores possuem traços narcisistas e destrutivos, estão freqüentemente inseguros quanto à sua competência profissional e podem exibir, às vezes, fortes características de personalidade paranóica, pela qual projetam em seus semelhantes sua "sombra", ou melhor, aquilo que não conseguem aceitar em si mesmos.

Apresentando extrema dificuldade para verdadeiramente admitir críticas, essas pessoas podem agir com desconfiança e excessiva suspeita em relação às atitudes alheias, a quem atribuem intenções maldosas; e, aparentando hipersensibilidade, podem exagerar o risco e a incerteza presentes em diversas situações; atitudes essas que ajudam a supervalorização de seu trabalho e o fortalecimento de sua auto-estima.

Ambiciosos e invejosos, esses indivíduos procuram aproveitar-se do trabalho alheio, sugando energias e realizações de outros para montarem uma pseudo-imagem de si próprios: verdadeiros "salvadores da pátria", os "guardiões das organizações".

Diz Lubit, no artigo Impacto dos gestores narcisistas nas organizações, que, por não tolerarem o sucesso de subordinados que possam distinguir-se mais do que eles, esses gestores normalmente afastam seus melhores funcionários, mormente se forem pessoas mais jovens com ou mais qualificações (formais ou informais) do que eles próprios. Mesmo que venham a aparentemente incentivar essas pessoas, temporariamente adotando uma postura "simpática" a elas, não tardam a "puxar-lhes o tapete", ou seja, a enfraquecê-las ou a eliminá-las da organização, sobretudo se manifestarem suas próprias opiniões, mostrando-se independentes Nossa experiência demonstra que seu "tipo preferido" é o indivíduo que trabalha muito ("o pé-de-boi"), não questiona nada ("o cordeiro") e, freqüentemente, enaltece o ego de seu superior em posição reverente ("o puxa-saco").

Geralmente o assédio moral nasce com pouca intensidade, como algo inofensivo, pois as pessoas tendem a relevar os ataques, levando-os na brincadeira; depois, propaga-se com força e a vítima passa a ser alvo de um maior número de humilhações e de brincadeiras de maut gosto. 
Isso provavelmente acontece justamente por que as vítimas temem fazer denúncias formais, com medo do "revide" que poderia ser a demissão ou o rebaixamento de cargo, por exemplo; além de que essas denúncias iriam tornar pública a humilhação pela qual passaram, o que as deixaria ainda mais constrangidas e envergonhadas. Assim, o medo (de caráter mais objetivo) e a vergonha (mais subjetiva, mas com conseqüências devastadoras) se unem, acobertando a covardia dos ataques.

Embora seus agressores tentem desqualificá-las, normalmente as vítimas não são pessoas doentes ou frágeis. São pessoas com personalidade, transparentes e sinceras que se posicionam, algumas vezes questionando privilégios, e não têm grande talento para o fingimento, para a dramaturgia.Tornam-se os alvos das agressões justamente por não se deixarem dominar, por não se curvarem à autoridade de um superior sem nenhum questionamento a respeito do acerto de suas determinações.

É o próprio assédio que pode vir a patologizar as vítimas, desencadeando um processo mimético em relação a que o agressor, individualmente ou em grupo, afirma sobre elas: que são desatentas, inseguras (daí serem hipersensíveis às críticas), quase paranóćcas.Referimo-nos ao agressor agindo sozinho ou em grupos, porque, de fato, no caso de um agressor que atue dentro de uma empresa, este pode aliciar colegas que, por receio ou interesse, aliem-se a ele em sua "perseguição" a um determinado funcionário, considerando que, agindo dessa forma, demonstram uma certa cumplicidade, na esperança da recompensa de uma não agressão futura em relação a si próprios. É o "esprit d'équipe" que, particularmente nessa situação, traduz a falsa idéia de que a "solidariedade" ao chefe pode conduzir à segurança e mesmo à ascensão dentro da empresa.

Um exemplo elucidativo desse processo mimético em que a vítima acaba por reproduzir aquilo que lhe é atribuído seria aquele em que se atribui ao sujeito agredido a pecha de ser desatento, não envolvido com seu trabalho, imperito. Em longo prazo, depois de alguns meses, às vezes até anos de sofrimento atroz, desencadeado por essa constante e desmerecedora "adjetivação" direta ou indireta, o indivíduo torna-se exatamente o que lhe foi atribuído. A vítima pode entrar em depressão e sofrer, por exemplo, um longo período de insônia, o que é comum nesse quadro depressivo. Dessa forma, ela pode acabar por se tornar realmente negligente no trabalho, não por seu desejo e sim pela pauperização, pela fragilização de sua saúde física e mental.

É interessante observarmos que em épocas passadas, no Brasil, o assédio moral se dava basicamente com o "peão", o serviçal sem maiores qualificações. Hoje, abrange todas as classes, infelizmente "democratizoutse" no mau sentido; juízes, desembargadores, professores universitários, médicos e funcionários de funções diversas, muitas vezes bastante qualificados, também são atingidos por esse fenômeno.

Apesar de a maioria das pesquisas apontarem que as mulheres são, estatisticamente falando, as maiores vítimas do assédio moral, também são elas as que mais procuram ajuda médica ou psicológica e, não raro, no seu próprio grupo de trabalho, verbalizando suas queixas, pedindo ajuda.

Em relação ao homem, sob alguns aspectos, essa situação é mais delicada, pois fere sua identidade masculina. Em um tipo de agressão que, como já vimos, é paulatina e quase-invisível, não raro quando a vítima se apercebe da situação o fenômeno destrutivo já se estabeleceu, o que a leva a um processo depressivo em que não encontra mais forças e em relação a que nem mesmo possui ânimo para reagir.

Essa atitude de aparente passividade, ou melhor, de ausência de ação, dentro de nossa cultura machista e preconceituosa é vista mais como um atributo feminino do que masculino, o que piora o quadro depressivo da vítima, pois rebaixa ainda mais sua auto-estima, ferindo sua identidade masculina. Assim, no caso masculino, tornar pública a sua humilhação associa-se a admitir sua impotência diante 
dos fatos, o que se lhe configura como o "fundo do poço", o auge de sua forçada degradação. Daí ocorrerem somatizações como úlcera, disfunções sexuais, eternas cefaléias etc.

\section{Tentativas de coibir o assédio moral}

Embora muitas das grandes empresas possuam código de ética - a maioria das 100 melhores empresas que estão no ranking da revista Exame o possuem - só essa conquista não é suficiente. O simples fato de termos um código penal que condene furtos, roubos, homicídios, latrocínios, seqüestros etc. não impede a sua ampla ocorrência.O que pode ser atestado e confirmado empiricamente pela simples leitura diária das manchetes de jornal.

Além dos códigos de ética, podem-se criar mecanismos, por meio do departamento de Recursos Humanos da empresa, para dar ao trabalhador agredido o direito de denunciar a agressão de que tenha sido vítima, por escrito e sigilosamente ; com esse fim, o indivíduo agredido pode utilizar caixas postais e mesmo "urnas" em dependências isoladas dentro da organização, para que, em tese, possa ter seu anonimato garantido. São passos para amenizar o problema, mas não bastam.

A nosso ver, as condições e a filosofia que determinam a hipercompetição é que devem mudar.Somente um efetivo processo de humanização do trabalho poderá fazer com que os "sintomas" dessa verdadeira doença retrocedam.

Poderíamos começar pela criação daquilo que Christophe Dejours, em várias de suas obras, chama de espaço público, ou espaço de discussão, ou seja, um local que, no caso, poderia existir dentro das próprias empresas, onde os membros da organização pudessem expor seus problemas, angústias e expectativas, facilitando o entendimento.Seria o caso, como diria Habermas, da "racionalidade instrumental", ou seja, da lógica do sistema, vir a ceder espaço à "ação comunicativa", que tenha por base argumentos justos e transparentes. . Em outros termos, tal discussão, que no atual momento nos parece utópica, pode levar as pessoas a perceberem que seu problema não é individual, que não lhes falta competência. Trata-se de um fenômeno que envolve interações sociais complexas e, portanto,as vítimas da violência não devem se culpar.

\section{Observações finais}

É dessa forma, parece-nos, por meio da organização do coletivo e de sua abertura dialógica que conduziria a uma sociedade mais democrática e, portanto, menos sujeita à violência, que o problema do assédio moral poderia vir a ser gradativamente minimizado.De fato, a saída está na organização do coletivo para que possamos transformar súditos em cidadãos. Relembrando um pensamento de Norberto Bobbio , um dos mais respeitados cientistas políticos da atualidade,em sua obra Liberalismo e democracia ,para tornar-se cidadão é necessário haver direitos iguais para todos, constitucionalmente garantidos, sem discriminação de qualquer tipo - sejam provenie ntes de sexo, religião, raça, classe social ou quaisquer outras. E como o momento histórico e o povo influem sobre esse elenco de direitos, pode-se afirmar que fundamentais são os direitos atribuídos a todos os cidadãos indistintamente e de forma absolutamente equânime.

Esses direitos fundamentais, é bom que se diga, indiretamente já fazem parte do acervo jurídico nacional, tal como o artigo $5^{\circ}$ da Constituição Federal, parágrafos II e III, que abrangem respectivamente o assédio sexual e o moral, o artigo 483 da CLT e mesmo os artigos 138,139 e 140 do Código Penal, relativos a crimes contra a honra, ou seja, calúnia, difamação e injúria; sem mencionar o artigo 146 - constrangimento ilegat do referido código, que também pode ser aplicado ao assédio 
sexual. Colocamos "indiretamente" porque a maior dificuldade no que concerne à penalização do assédio moral é justamente a sua "invisibilidade" e, portanto, o alto grau de subjetividade envolvido na questão. O nexo causal, ou seja, a comprovação da relação entre a conseqüência (no caso, o sofrimento da vítima) e sua causa (no caso, a agressão), indispensável na esfera criminal, nem sempre é aparente, na medida em que tais humilhações são mormente perpetradas "com luvas", ou seja, sem deixar as digitais do agressor.

No entanto, apesar dessa dificuldade de penalização, como já observamos, devida ao fator subjetivo que envolve esse tipo de delito, vários países já têm uma legislação específica para criminalizar o assédio moral no trabalho. É o caso da Alemanha, da Itália, da França, da Austrália, dos Estados Unidos e da Suíça.

No Brasil, vereadores e deputados têm tentado criar uma legislação mais direcionada a esse fenômeno, no intuito de chamar atenção para sua gravidade. É o caso de Arselino Tatto, vereador do PT, que teve seu projeto de lei aprovado em janeiro de 2002, de Marcos de Jesus, deputado pelo PL, que altera o Código Penal introduzindo o inciso 146 A e do projeto de lei de Antonio Mentor, deputado estadual pelo PT.

Como encerramento, fica uma sugestão para reflexão: se não nos solidarizarmos com as vítimas de assédio moral por senso de justiça e bondade, deveríamos fazê-lo por inteligência... Amanhã qualquer um de nós poderá vir a ser uma delas... Sobretudo em uma estrutura social em que, como vimos, impera o egoísmo e a hipercompetitividade.

De fato, em uma sociedade cuja base cultural fosse a fraternidade, o assédio moral simplesmente não existiria, ou se restringiria às patologias individuais. Mas, enquanto vivermos em uma sociedade que valoriza muito mais a capacidade de competir e vencer do que o altruísmo e a generosidade, com certeza esse tipo de coação moral continuará acontecendo.

Nesse sentido é que podemos afirmar que a punição a esses agressores, que agem de maneira torpe egoísta e covarde - é bem- vinda. Impõe limites e cria barreiras a procedimentos antiéticos.

Continuemos, pois, em nossa luta solidária por uma sociedade mais justa e menos prepotente, em que possamos ter direito a expressar nossas opiniões sem sofrermos qualquer tipo de retaliação. Oxalá venhamos algum dia a viver em uma sociedade plenamente democrática.

Pensata recebida em 10.04.2003. Aprovada em 15.09.2003.

\section{Roberto Heloani}

Professor e pesquisador na FGV - EAESP, UNICAMP e USM..

E-mail: jheloani@ fgvsp.br

Endereço: FGV-EAESP - Av. Nove de Julho, 2029 - 10ª andar, São Paulo - SP, 01313-902. 